BMJ Open

Diabetes

Research

\& Care

\title{
Drivers of weight loss in a CDC- recognized digital diabetes prevention program
}

\author{
Stefanie L Painter (D) , ${ }^{1}$ Wei Lu, ${ }^{1}$ Jennifer Schneider, ${ }^{1}$ Roberta James, ${ }^{1}$ \\ Bimal Shah ${ }^{1,2}$
}

To cite: Painter SL, Lu W, Schneider J, et al. Drivers of weight loss in a CDCrecognized digital diabetes prevention program. BMJ Open Diab Res Care 2020;8:e001132. doi:10.1136/ bmjdrc-2019-001132

- Additional material is published online only. To view please visit the journal online (http://dx.doi.org/10.1136/ bmjdrc-2019-001132).

Received 17 December 2019 Revised 22 April 2020 Accepted 30 May 2020
Check for updates

\section{(c) Author(s) (or their} employer(s)) 2020. Re-use permitted under CC BY-NC. No commercial re-use. See rights and permissions. Published by BMJ.

${ }^{1}$ Livongo Health, Mountain View, California, USA ${ }^{2}$ Duke University School of Medicine, Duke University, Durham, North Carolina, USA

Correspondence to Dr Stefanie L Painter; spainter@livongo.com

\section{ABSTRACT}

Introduction To investigate the impact of the digital Livongo Diabetes Prevention Program (DPP) on weight at 12 months, understand participants' self-monitoring behaviors associated with greater weight loss, and evaluate the impact of coaching interactions on more frequent self-monitoring behaviors.

Research design and methods A retrospective analysis was performed using data from 2037 participants enrolled in the Livongo DPP who completed lesson 1 and recorded a starting weight during 2016-2017. Self-monitoring behaviors, including weigh-ins, food logging, activity, and coach-participant interactions, were analyzed at 6 and 12 months. Subgroup analysis was conducted based on those who were highly engaged versus those minimally engaged. Multiple regression analysis was performed using demographic, self-monitoring, and lesson attendance data to determine predictors of weight loss at 12 months and coaching impact on self-monitoring. Results Participants had a mean age of 50 years (SD $\pm 12)$, with a starting weight of $94 \mathrm{~kg}(\mathrm{SD} \pm 21)$, were college-educated (78\%), and were female (74\%). Overall, participants lost on average $5.1 \%$ of their starting weight. Highly engaged participants lost $6.6 \%$ of starting body weight, with $25 \%$ losing $\geq 10 \%$ at 12 months. Logistic regression analysis showed each submitted food log was associated with $0.23 \mathrm{~kg}(p<0.05)$ weight loss, each lesson completed was associated with $0.14 \mathrm{~kg}(\mathrm{p}<0.05)$ weight loss, and a week of 150 active minutes was associated with $0.1 \mathrm{~kg}(p<0.01)$ weight loss. One additional coachparticipant message each week was associated with 1.4 more food logs per week, $1.6 \%$ increase in weeks with four or more weigh-ins, and a $2.7 \%$ increase in weeks with 150 min of activity.

Conclusions Food logging had the largest impact on weight loss, followed by lesson engagement and physical activity. Future studies should examine further opportunities to deliver nutrition-based content to increase and sustain weight loss for DPP.

\section{INTRODUCTION}

Pre-diabetes is classified by a fasting blood sugar level between 100 and $125 \mathrm{mg} / \mathrm{dL}$ or hemoglobin A1c between $5.7 \%$ and 6.4\%. ${ }^{1}$ Pre-diabetes affects nearly $40 \%$ of the US population and increases the risk of developing type 2 diabetes (T2DM), heart

\section{Significance of this study}

What is already known about this subject?

- Diabetes prevention programs recognized by the Centers for Disease Control and Prevention are effective at producing clinically significant weight loss, and individuals who are more engaged in program features (ie, food logging, attending lessons, and physical activity) are more likely to experience greater weight loss.

What are the new findings?

- The number of food logs per week, the total number of lessons attended, and the percentage of weeks with 150 min of activity were determined to be major predictors of weight loss at 12 months.

- Participant interaction with their coach increased the likelihood that a participant would be more engaged with program components, such as food logging, weigh-ins, and getting 150 min of activity each week.

How might these results change the focus of research or clinical practice?

- Understanding the behaviors and specific program components that are associated with greater weight loss in a technology-based diabetes prevention program can influence best practices for program creation and coaching to improve outcomes and decrease participants' risk factors for developing type 2 diabetes.

disease, and stroke; however, only about one in eight adults are aware they have the condition. ${ }^{2}$ The National Diabetes Prevention Program established in 2010 by the Centers for Disease Control and Prevention (CDC) provides a 12-month structured program for individuals with pre-diabetes to achieve a moderate $5 \%-7 \%$ weight loss and increase physical activity to $150 \mathrm{~min}$ per week, which has shown to prevent T2DM by $58 \%{ }^{13}$ CDC-recognized programs include CDC-approved curriculum, a specially trained lifestyle coach, and a support group either in person or online. ${ }^{3}$ 
The number of CDC-recognized digital diabetes prevention programs (DPP) is increasing with the growth in technological integration in healthcare. Studies have shown that digital DPP programs have similar participation rates and outcomes as inperson programs. ${ }^{4}$ Numerous digital DPP programs have reported outcomes ranging from $4.3 \%$ to $7.5 \%$ weight loss. ${ }^{5-10}$ Previous studies have also shown an association between coaching and engagement, specifically around self-monitoring components of an intervention. ${ }^{11-13}$ Since only $20 \%$ of individuals are successful at weight loss maintenance at 12 months, determining factors and self-monitoring behaviors that promote successful weight loss and weight maintenance is essential for diabetes prevention. ${ }^{14}$

Livongo DPP is a digital CDC-recognized program offering participants interactive lessons and live personal expert coaching. The purposes of this study were (1) to understand participants' self-monitoring behaviors associated with greater weight loss and (2) to evaluate the impact of coaching interactions on more frequent self-monitoring behaviors.

\section{METHODS}

\section{Study design}

A retrospective analysis was performed to analyze participants' weight loss, program engagement, self-monitoring behaviors, and coach-participant interactions at 6 and 12 months. Subgroup analysis was also performed on highly engaged participants, in addition to multiple regression analysis to determine predictors of weight loss at 12 months and the impact of coaching on the predictors of weight loss in the highly engaged participants.

\section{Participants}

Participants included members of Livongo DPP who enrolled through an employer-sponsored program as part of their employer's health benefits package. Members were considered eligible if they met the CDC program eligibility requirements, were determined at risk through the CDC Prediabetes Screening Test, were previously diagnosed with gestational diabetes, or diagnosed with pre-diabetes through blood glucose testing (see box 1), and voluntarily enrolled into the program between May 23, 2016 and September 30, 2017, to allow for 12 months of participation in Livongo DPP. ${ }^{1516}$ During registration into the program, participants confirmed acknowledgment of Livongo's (formerly Retrofit) terms and conditions and privacy policy, which stated that participants understand that all data collected could be used for a variety of reasons including research. ${ }^{17}$ Due to exempt status, informed consent was not required. Participants were included in the study if they completed lesson 1 and had a starting weight. Any participant enrolled without both lesson 1 completed and a starting weight was excluded from the study.
Box 1 CDC-recognized diabetes prevention program

\section{eligibility requirements}

The following criteria must be met to be eligible for a CDC-recognized Diabetes Prevention Program:

- At least 18 years of age and

- Be considered overweight by a body mass index $\geq 25$ ( $\geq 23$ is Asian) and

- No previous diagnosis of type 1 or type 2 diabetes and

- Within the past year have a blood test result of the following: Hemoglobin $\mathrm{A} 1 \mathrm{C}=5.7 \%-6.4 \%$ or

Fasting plasma glucose $=100-125 \mathrm{mg} / \mathrm{dL}$ or

Two-hour plasma glucose (after 75gm glucose load) $=140-$ $199 \mathrm{mg} / \mathrm{dL}$ or

Previously diagnosed with gestational diabetes

CDC, Centers for Disease Control and Prevention.

\section{Program}

\section{Livongo Diabetes Prevention Program}

Livongo's CDC-recognized DPP lifestyle intervention program was created as a commercial entity selling this program into health plans, health systems, and selfinsured employers. The Livongo DPP included an expertmoderated online community, interactive meetings and lessons, video conferencing coaching sessions, and unlimited coaching and community conversations through electronic messaging via mobile application (available through Google Play for Android phones and Apple App Store for iOS phones) or website served through an existing national weight loss company platform producing clinically significant weight loss outcomes. ${ }^{18-20}$ Thirty-one interactive, digital, skill-building lessons were available and emphasized self-monitoring of weight, food, and activity on an ongoing basis (see online supplementary table S1 for DPP lesson schedule and topics). Online communities consisted of 15-25 participants for social support. Each participant was provided a wireless Bluetooth scale, personal web-based dashboard, and mobile phone application for viewing lessons, informational content, self-monitoring, and communication with a community and expert coach. The mobile phone application also received and documented historical data from the Bluetooth scale and fitness tracker, if the participant provided access. All aspects of the program were available through the mobile application or website.

\section{Engagement \\ Highly engaged participants}

Highly engaged participants met the CDC highengagement criteria by completing nine lessons within months $1-6$ and three lessons within months $7-12$ of the program with a minimum of 9 months between first and final lessons completed. ${ }^{21}$

\section{Minimally engaged participants}

Minimally engaged participants include all participants not meeting the CDC high-engagement criteria. ${ }^{21}$ 


\section{Measures}

All participants self-reported demographic characteristics at program registration, including age, gender, height, weight, education level, and risk factors for diabetes (ie, history of gestational diabetes, blood glucose test indicating pre-diabetes or the CDC Prediabetes Screening Test) (see box 1). Self-monitoring behaviors were captured remotely through program platform, including weigh-ins, food logging, and physical activity (ie, days wearing activity tracker, step counts, and active minutes) at 12 months.

\section{Measures of self-monitoring behaviors}

Weigh-ins

All participants received a wireless connected scale that automatically connected with the mobile app via Bluetooth and securely transmitted weight data to a central data server for data collection and analytics. Manual entry of weight data was permissible if participants had difficulty setting up or syncing the provided Bluetooth wireless scale. Participants were provided instructions on how to use the scale and given unlimited access to Livongo DPP customer support. Baseline weight was defined as the average weight measurement received from the participant during the week after DPP lesson 1. Participants were encouraged to monitor weight by stepping on the scale and syncing weight daily with a program recommendation of no less than four weigh-ins weekly. ${ }^{22-24}$ The weight outcome at 6 months and 12 months was defined as the average weight measurement received from the participant during days 159-187 and days 300-367 after the first session, respectively. Average weight, change in pounds, percentage of weight change, and change in body mass index (BMI) were reported at 6 and 12 months for all participants and by participants' level of program engagement. BMI was calculated as weight $(\mathrm{kg}) /$ height $^{2}$ $\left(\mathrm{m}^{2}\right)$ using self-reported height at baseline and weight captured remotely from connected scales at 6 and 12 months. Weight at 6 months was captured at the participant's program day 180 or, if not available, the closest weight within the window of 21 days prior to 7 days after day 180 . Weight at 12 months was captured at program day 365 or, if not available, between 60 days prior to 7 days after day 365 . Any participant weight input that was $\geq 5 \%$ change from both the median and the preceding value or both the median and the following value was flagged as an outlier and assigned a missing value.

\section{Food logging}

A private dashboard available through the website or mobile application allowed participants to record daily dietary intake through photo or text. Participants could $\log$ meals, snacks, treats, and beverages, along with a description, quantity, and photo. Each individual meal, snack, treat, or beverage was considered a single food log entry. Participants were encouraged to $\log$ all food and beverages consumed throughout the program with no limit on the number of food logs entered daily.

\section{Physical activity}

Physical activity was defined as the amount of time logged by the participant into the dashboard $(1.5 \%$ of recorded activity entries) or the amount of time synced from their activity tracker (98.5\% of recorded activity entries). The activity tracker calculated active minutes using metabolic equivalents (METs) and intensity of movement and provided this back to the participant through the mobile application and website dashboard.$^{25}$ Participants were encouraged to achieve $150 \mathrm{~min}$ of physical activity each week per CDC recommendations of the National Diabetes Prevention Program. Participants' active minutes per week were averaged, and a combined total of highly active (3 MET) and fairly active minutes per week was averaged to determine the percentage of weeks in program meeting the CDC recommendation of $150 \mathrm{~min}$ of physical activity each week.

\section{Measures of coach-participant interactions \\ Interactive lessons}

Thirty-one interactive, digital, skill-building lessons were provided emphasizing self-monitoring of weight, food, and activity (see online supplementary table S1 for DPP lesson schedule and topics). Lesson 1 was an interactive group lesson, and all the following lessons were completed individually through the program app or website. Lessons were offered weekly for the first 9 weeks and biweekly for the remaining 43 weeks of the program. Participants were encouraged to attend all lessons.

\section{Coaching sessions}

Participants were provided two $30 \mathrm{~min}$ one-on-one coaching sessions with an expert-certified DPP lifestyle coach. In addition to DPP lifestyle certification, Livongo expert coaches are registered dietitians, exercise physiologists, nurses, or social workers with master's or doctoral degrees. Coaching sessions were scheduled at the participant's convenience.

\section{Coach/participant messages}

Participants were able to send unlimited messages to their expert coach via the mobile app or website with a required coach response time within 24 hours Monday through Friday and within 48 hours Saturday and Sunday. Participants also had access to post messages within the mobile app or website to their assigned online community to receive support from and provide support to other participants.

\section{Expert coach feedback}

Livongo DPP coaches were required to review participants' progress, food and exercise logs, and provide feedback two times per week between weeks 1 and 25 and once per week between weeks 26 and 52. Feedback was provided asynchronously and received as a written message within the participant's mobile app or web page profile. 


\section{Statistical analysis}

A retrospective analysis was performed to evaluate the effect of engagement, self-monitoring behaviors, and coach-participant interactions on weight loss outcomes during the 12-month Livongo DPP intervention. Descriptive statistics were used to describe participants' demographics, characteristics, and distribution of population by program engagement. Program participation through self-monitoring and coach-participant interactions was analyzed at 6 and 12 months for all participants by engagement criteria and weight loss categories. Weight loss categories were set from the CDC DPP recommendations of losing $5 \%-7 \%$ of the starting weight and clinical recommendations of $10 \%$ weight loss provided by the National Institute of Health. ${ }^{326}$ The mean value and SD or the percentage of total population was reported for each program feature. $P$ values less than 0.05 were considered statistically significant. No adjustment for multiple comparisons was made.

\section{Primary analysis}

The association between program participation and percentage of weight loss was measured using multivariable linear regression modeling with normal distribution, controlling for participant-level characteristics of gender, age, education level, and initial weight. Variables measuring different attributes of program participation, including the total number of lessons, weigh-ins, food logs, weekly activity levels, coach messages, and member group conversations, were included in the model to test their adjusted association with weight loss outcomes. The quadratic transformation of the average number of food logs per week was included in the model to address potential decrease in marginal effect of food logs per week on weight loss outcomes as frequency of food logging increases. Interaction of the average number of food logs per week with the number of coach messages per week was included to check for additional changes in food logs on different coach message frequencies. Standardized coefficients are reported to account for different program features measured in different units of measurement and allowed ranking of program activities.

\section{Secondary analysis}

Previous studies have shown an association between coaching and engagement, specifically around selfmonitoring components of an intervention. ${ }^{11-13}$ Therefore, multivariable regression modeling with normal distribution was performed to evaluate associations between coach-participant messages at 6 months and food logging, weigh-ins, and active minutes per week at 12 months, adjusting for participant characteristics of starting weight, gender, age, education, and engagement status. Multivariable logistic regression was also used to evaluate the association of coaching with the likelihood of being highly engaged.

\section{RESULTS}

A total of 2161 individuals enrolled during this period, and 2037 attended lesson 1 and provided a starting weight as inclusion criteria for participation in the study. Of the 2037 participants, $658(32.3 \%)$ were considered to be highly engaged and $1379(66.7 \%)$ were considered minimally engaged. Of the highly engaged participants, $649(98.6 \%)$ registered a 6-month weight and 640 $(97.3 \%)$ registered a 12-month weight. Of the minimally engaged participants, $834(60.5 \%)$ had a 6 -month weight and $715(51.8 \%)$ had an available 12-month weight. Overall, $98.1 \%$ of recorded weights were automatically uploaded from the connected scale, while the remaining were manually entered by the participant.

Table 1 shows the demographic details at enrollment, engagement status, and weight loss outcomes. Minimally engaged participants were younger than highly engaged participants, had a higher starting weight, and had a higher BMI than highly engaged participants at baseline. Highly engaged participants were more likely to have a college education, more likely to be male, and with blood glucose test indicating diabetes risk compared with minimally engaged participants. Overall, $43 \%$ of participants of Livongo DPP lost on average $5.1 \%$ of their weight or $5.0 \mathrm{~kg}$ by 12 months. More than $50 \%$ of the highly engaged population and $35 \%$ of minimally engaged participants achieved clinically significant weight loss $(>5 \%)$ at 12 months, with $25 \%$ of highly engaged participants losing $\geq 10 \%$ at 12 months. The percentage of weight and the average pounds lost are shown in online supplementary figure $\mathrm{S} 1$.

\section{Program participation \\ Self-monitoring}

Self-monitoring behaviors including weigh-ins, food logging, and physical activity over 12 months are reported by engagement and weight loss category (see online supplementary table S2 for program participation at 6 months and online supplementary table S3 for program participation at 12 months). Across all measures, a significant increase in frequency of self-monitoring behaviors was seen in highly engaged compared with minimally engaged participants.

On average, participants weighed in four times per week and entered 13 food logs per week. Highly engaged participants weighed in significantly more than minimally engaged ( 4.6 vs $3.2, \mathrm{p}<0.001$ ), recorded approximately 13 more food logs per week ( 19.4 vs 6.4 , $\mathrm{p}<0.001$ ), and logged food three more days per week (4.6 vs 1.7 , $\mathrm{p}<0.001)$. Participants losing $\geq 10 \%$ weighed in and logged food significantly more than those losing $<5 \%$ (4.2 vs 3.6 , $\mathrm{p}<0.001$ and 17.1 vs $10.1, \mathrm{p}<0.001$, respectively).

All participants wore activity trackers 4 days per week on average, achieving an average of 5333 steps daily, with 20 out of 52 weeks in program exceeding 150 active minutes. Highly engaged participants wore their activity tracker nearly 2 days more per week than minimally engaged (5.3 vs 3.2, $\mathrm{p}<0.001$ ), achieving significantly 
Table 1 Demographics summarized using mean (SD) and percentages

\begin{tabular}{|c|c|c|c|c|}
\hline & $\begin{array}{l}\text { All participants* } \\
\mathrm{n}=2037\end{array}$ & $\begin{array}{l}\text { Highly engaged }+ \\
\mathrm{n}=658\end{array}$ & $\begin{array}{l}\text { Minimally engaged } \neq \\
\mathrm{n}=1379\end{array}$ & $P$ value \\
\hline Age (years), mean (SD) & 49.7 (12.0) & $54.8(10.6)$ & $47.3(11.9)$ & $<0.001$ \\
\hline Starting weight $(\mathrm{kg})$, mean (SD) & $93.9(21.0)$ & $90.6(20.1)$ & $95.5(21.2)$ & $<0.001$ \\
\hline Starting BMI $\left(\mathrm{kg} / \mathrm{m}^{2}\right)$, mean (SD) & $33.3(6.8)$ & $32.2(6.4)$ & $33.8(7.0)$ & $<0.001$ \\
\hline \multicolumn{5}{|l|}{ Age group } \\
\hline $18-44(\%)$ & 32.3 & 14.7 & 40.7 & $<0.001$ \\
\hline 45-64 (\%) & 57.4 & 67.8 & 52.4 & $<0.001$ \\
\hline $65+(\%)$ & 10.3 & 17.5 & 6.9 & $<0.001$ \\
\hline \multicolumn{5}{|l|}{ BMI } \\
\hline Normal (\%) & 5.1 & 6.5 & 4.4 & 0.060 \\
\hline Overweight (\%) & 33.1 & 39.1 & 30.2 & $<0.001$ \\
\hline Class I obesity (\%) & 28.8 & 28.1 & 29.1 & 0.650 \\
\hline Class II obesity (\%) & 17.5 & 13.5 & 19.4 & 0.001 \\
\hline Class III obesity (\%) & 15.6 & 12.8 & 16.9 & 0.010 \\
\hline College graduate (\%) & 77.7 & 81.8 & 75.8 & 0.002 \\
\hline Not a college graduate (\%) & 22.1 & 17.6 & 24.2 & $<0.001$ \\
\hline Education undisclosed (\%) & 0.2 & 0.6 & 0.0 & 0.050 \\
\hline Male (\%) & 26.0 & 28.9 & 24.6 & 0.040 \\
\hline \multicolumn{5}{|l|}{ Risk factor for diabetes } \\
\hline Blood glucose test (\%) & 33.8 & 39.4 & 31.1 & $<0.001$ \\
\hline Gestational diabetes (\%) & 2.2 & 3.2 & 1.7 & 0.060 \\
\hline CDC risk test (\%) & 95.2 & 96.1 & 94.9 & 0.220 \\
\hline Weight loss at 12 months (\%) & 5.1 & 6.6 & 3.8 & 0.006 \\
\hline
\end{tabular}

*All participants: any participant enrolled in Livongo DPP who attended lesson 1 and provided a starting weight.

†Highly engaged participants: participants who met the CDC high-engagement criteria by completing nine lessons within months 1-6 of the program and three lessons within months $7-12$ of the program with a minimum of 9 months between first and final lessons completed. ${ }^{21}$ ¥Minimally engaged participants: all participants not meeting the CDC high-engagement criteria. ${ }^{21}$

BMI, body mass index; CDC, Centers for Disease Control and Prevention; DPP, diabetes prevention program.

more steps per day $(6564.9$ vs $4045.6, \mathrm{p}<0.001)$ and more weeks with $150 \mathrm{~min}$ of activity $(54.9 \%$ vs $24.9 \%$, $\mathrm{p}<0.001)$. Participants who lost $\geq 10 \%$ wore their activity tracker significantly more days than those who lost $<5 \%$ (4.7 vs $3.8, \mathrm{p}<0.001)$. Daily step counts are significantly higher in participants who lost $\geq 10 \%$ versus those losing $<5 \%$ (6844.4 vs 4637.5, p<0.001). Lastly, participants with $\geq 10 \%$ weight loss achieved significantly more weeks of $150 \mathrm{~min}$ of activity than those with $<5 \%$ weight loss $(51.9 \%$ vs $31.3 \%, \mathrm{p}<0.001)$.

Overall all participants on average weighed in approximately four times per week, logged 13 food logs per week over 3 days per week, wore activity tracker 4 days per week, performed $150 \mathrm{~min}$ of activity in 20 out of 52 program weeks (39\%), and achieved approximately 5300 steps per day. Highly engaged participants achieved significantly higher levels of self-monitoring, including weighing approximately five times per week, logging 20 food logs per week over 5 days per week, wearing activity tracker 5 days per week, performing $150 \mathrm{~min}$ of activity $55 \%$ of program weeks, and achieving over 6500 steps per day.
Participants losing $>5 \%$ had significantly higher levels of self-monitoring than participants losing $<5 \%$.

Participants attended, on average, 17 of the 31 lessons provided during the 12-month program. Coaches initiated interaction with participants two to three times each week, 1-2 days per week, while participants initiated interaction with their expert coach up to one to two times each week, 1 day per week overall. Highly engaged and participants losing $\geq 7 \%$ engaged more in their community than other weight loss categories.

\section{Predictors of weight loss}

In a multiple regression analysis using demographics, selfmonitoring, and coach-participant interaction measures, significant predictors of weight loss at 12 months for the highly engaged included food logs per week, total number of lessons attended, and percentage of weeks with $150 \mathrm{~min}$ of activity. Using standardized coefficient, the number of food logs per week had the highest influence on percent weight loss at 12 months over total lessons attended and percentage of weeks with $150 \mathrm{~min}$ 
of activity. Specifically, one more food log per week, one more lesson as offered per week, and one more week of 150 active minutes were associated with $0.5 \mathrm{lb}(0.3 \%$, $\mathrm{p}<0.05), 0.3 \mathrm{lb}(0.1 \%, \mathrm{p}<0.05)$, and $0.2 \mathrm{lb}(0.1 \%, \mathrm{p}<0.01)$ weight loss at 12 months, respectively, resulting in an additional cumulative $1.0 \mathrm{lb}(0.5 \%)$ of weight loss. See online supplementary table S4 for a complete list of variables, coefficient, and standard coefficients.

\section{Coach-participant interaction}

Coach-participant interactions are reported in tables 2 and 3. Table 2 includes lesson and coaching session attendance. Table 3 includes food and exercise log feedback frequency, frequency of messages initiated by a coach, and frequency of messages initiated by a participant (see online supplementary table S2 for program participation at 6 months). Highly engaged participants were more likely to post messages to coach ( 1.8 vs $1.1, \mathrm{p}<0.001)$ than minimally engaged, and received more messages (3.0 vs $2.1, \mathrm{p}<0.001)$ and food log feedback ( 1.4 vs $0.9, \mathrm{p}<0.001)$ from coaches.

\section{Impact of coaching on predictors of weight loss in the highly engaged}

While coach-participant messages were not shown to be significant predictors of weight loss at 12 months, coaching in the form of coach-participant messages was associated with increase in the self-monitoring behaviors of food logging, weigh-in frequency, and activity level.

Participants with one more coach-participant message each week during the initial 6 months of their program had a 32.3\% higher likelihood of being highly engaged than those with no coach-participant messaging. Additionally, participants are more likely to be highly engaged when male, older, and with a lower starting weight.

During the first 6 months of a participant's program, an increase in coach-participant messages per week was associated with an increase in the average number of food logs per week, an increase in weeks with four or more weigh-ins, and an increase in the number of weeks with 150 min or more of activity for the following 6-month period. One additional coach-participant message each week in the initial 6 months was associated with 1.40 more food logs per week, a $1.6 \%$ increase in weeks with four or more weigh-ins, and a $2.7 \%$ increase in percentage of weeks with $150 \mathrm{~min}$ or more of activity. Each outcome variable increased when a participant was male, older, and had a lower starting weight. This model was tested in the all participants group and resulted in similar findings.

\section{DISCUSSION}

Our study highlights the key components of a CDCrecognized digital DPP associated with weight loss over 12 months, which is the most significant predictor of diabetes prevention. Interaction with a coach via food logging was associated with the most weight loss, followed by lesson attendance and physical activity.

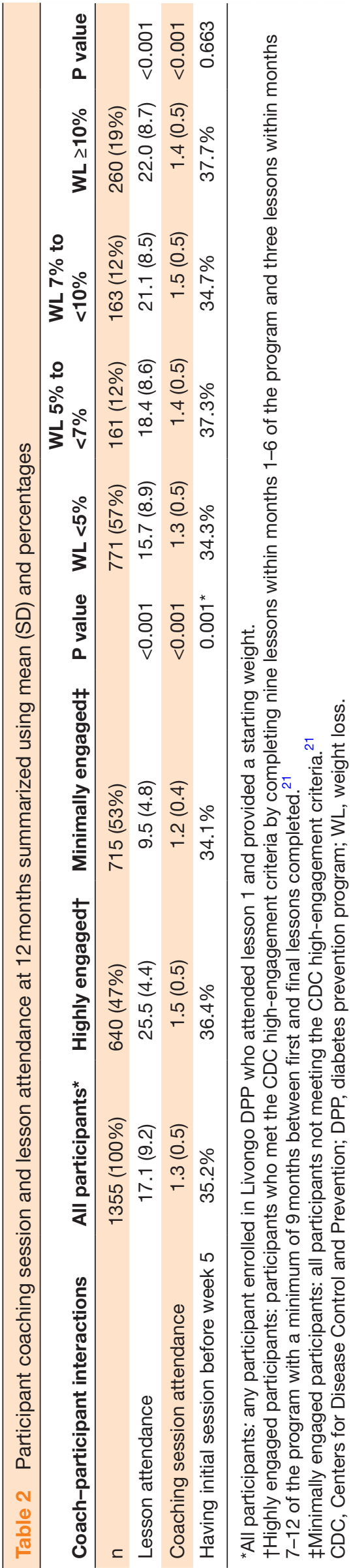




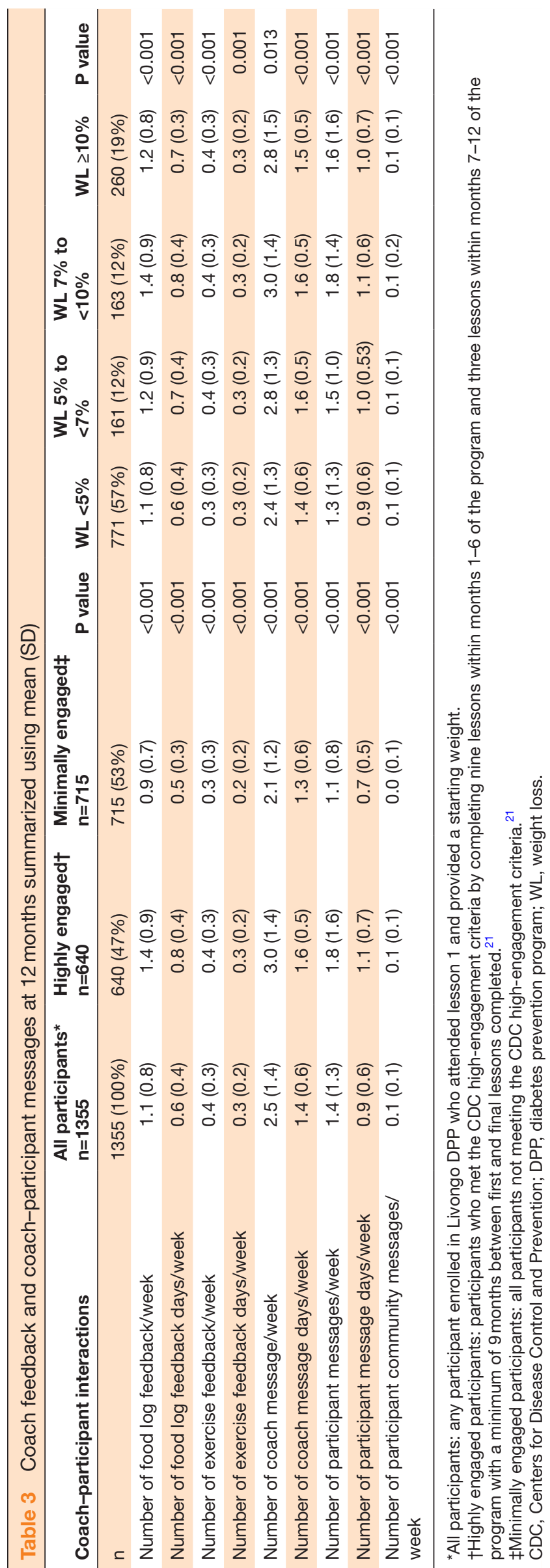

Food logging, lesson attendance, and physical activity have been previously examined as potential predictors of weight loss in DPP participants. Similar to other studies, we showed that a higher adherence to food logging, lesson attendance, and achieving $150 \mathrm{~min}$ of physical activity each week is consistently associated with greater weight loss and program engagement. ${ }^{7-9} 19$ 27-35 Providing food log feedback has been shown to increase self-monitoring, and given that coaches in the Livongo DPP program provided feedback this feature could have been a factor that resulted in increased food logging for this population. ${ }^{36}$ Additional analysis did show an association between coach-participant interactions with the likelihood of being highly engaged and increased food logging, weigh-ins, and physical activity.

Traditionally, CDC-recognized DPP programs are delivered inperson and do not require the addition of technology to assist in coaching between lessons and self-monitoring. The number of digital DPP programs is increasing; however, there is currently a lack of literature available around CDC-recognized digital DPP programs, their outcomes, and utilization of program components. While previous programs have reported outcomes, lesson attendance, and engagement, our study is able to provide more indepth data around using technology to enhance food logging, tracking physical activity, and in between lesson coach-participant interactions. ${ }^{7-9} 37$

Including technology with human coaching into DPP programs can increase scalability, while maintaining successful outcomes. Technology offers two components: (1) removal of human error in self-monitoring and (2) real-time coaching. When self-monitoring, unintentional human error can occur by forgetting to write down all food consumed, having a lack of knowledge around measuring portions, or poor estimation of time spent doing physical activity, for example. Using food tracking apps that allow for photo food logging requires logging in real time and clearly depicts exact portions consumed, which can be viewed by a coach to provide more timely feedback. In addition, activity trackers allow for a higher quality and larger volume of data collection by decreasing user effort and error, and these data can be wirelessly uploaded and made viewable for coaching. Both of these features were available for participants enrolled in the Livongo DPP intervention.

With digital health quickly growing, this study should be seen as an opportunity to understand how technology can be leveraged for scalability of DPP programs. Numerous studies support the importance of coaching for behavior change; however, it is costly. This study provides a retrospective view to reveal opportunities for prospective studies, specifically to use coaches for personalized feedback and education, and technology to use for self-monitoring reminders and data gathering. The collective data can be efficiently optimized to better inform interventions for behavior change by the coach and the program as a whole. 


\section{Strengths and limitations}

This study has several strengths, including the reporting of real-world weight loss outcomes of a CDC-recognized DPP program, as well as insight into the demographics, self-monitoring behaviors, and coach-participant interactions that drive engagement and weight loss. Participants were not provided with additional incentives to participate in the study beyond the DPP program being provided as a free benefit through their employer's benefit package. All members who attended lesson 1 and provided a starting weight were included in the all participants group and analyzed as the intention-to-treat population.

The study also had some limitations, including the retrospective analysis study design, which does not allow for any causal inferences based on the critical observations. Also, the use of a real-world population does not allow researchers to know if participants were integrating other self-monitoring devices or practices outside of Livongo DPP components and recommendations.

\section{CONCLUSION}

In conclusion, Livongo DPP's highly engaged participants lost $>5 \%$, and $25 \%$ of these participants lost $\geq 10 \%$ at 12 months. Three critical components (food logging, activity frequency, and lesson participation) were most strongly associated with participants' weight loss, and coaching was associated with increased self-monitoring behaviors. Our study shows that efforts to further enhance engagement in participation of these activities, which could be strengthened by personalized digital and live coaching to stimulate sustainable behavior change, could lead to more individuals achieving weight loss and reduce the risk of progression of high-risk individuals to diabetes.

Contributors Conception and design of the study: SLP, WL, JS, RJ, and BS. Acquisition of data: WL and RJ. Analysis and/or interpretation of data: SLP, WL, RJ, and BS. Drafting the manuscript: SLP, WL, RJ, and BS. Revising the manuscript critically for important intellectual content: SLP, WL, JS, RJ, and BS. Approval of the version of the manuscript to be published: SLP, WL, JS, RJ, and BS.

Funding The authors have not declared a specific grant for this research from any funding agency in the public, commercial or not-for-profit sectors.

Competing interests All authors are employed by Livongo Health.

Patient consent for publication Not required.

Ethics approval Exemption was granted by the Western Internal Review Board (\#1-1039270-1) due to its retrospective analysis design and use of de-identified data set.

Provenance and peer review Not commissioned; externally peer reviewed.

Data availability statement All data relevant to the study are included in the article or uploaded as supplementary information.

Open access This is an open access article distributed in accordance with the Creative Commons Attribution Non Commercial (CC BY-NC 4.0) license, which permits others to distribute, remix, adapt, build upon this work non-commercially, and license their derivative works on different terms, provided the original work is properly cited, appropriate credit is given, any changes made indicated, and the use is non-commercial. See: http://creativecommons.org/licenses/by-nc/4.0/.
REFERENCES

1 Diagnosing Diabetes and Learning About Prediabetes. American diabetes association 2014. Available: http://www.diabetes.org/areyou-at-risk/prediabetes/?loc=atrisk-slabnav [Accessed Dec 2018].

2 Diabetes Report Card, 2017. Centers for disease control and prevention 2018. Available: https://www.cdc.gov/diabetes/library/ reports/reportcard/index.html [Accessed Sep 2019].

3 National Diabetes Prevention Program. Centers for disease control and prevention 2018. Available: https://www.cdc.gov/diabetes/ prevention/index.html [Accessed Dec 2018].

4 Vadheim LM, Patch K, Brokaw SM, et al. Telehealth delivery of the diabetes prevention program to rural communities. Transl Behav Med 2017;7:286-91.

5 Alwashmi MF, Mugford G, Abu-Ashour W, et al. A digital diabetes prevention program (transform) for adults with prediabetes: secondary analysis. JMIR Diabetes 2019;4:e13904.

6 Lark Health. From cost savings to healthier members, lark delivers clinical outcomes. Available: https://www.lark.com/outcomes [Accessed Apr 2020].

7 Michaelides A, Raby C, Wood M, et al. Weight loss efficacy of a novel mobile diabetes prevention program delivery platform with human coaching. BMJ Open Diabetes Res Care 2016;4:e000264

8 Sepah SC, Jiang L, Ellis RJ, et al. Engagement and outcomes in a digital diabetes prevention program: 3-year update. BMJ Open Diabetes Res Care 2017;5:e000422.

9 Sepah SC, Jiang L, Peters AL. Long-Term outcomes of a webbased diabetes prevention program: 2-year results of a single-arm longitudinal study. J Med Internet Res 2015;17:e92.

10 Vida Health. Personalized virtual care platform for chronic and behavioral health conditions. Available: https://www.vida.com/ [Accessed Apr 2020].

11 Reid N, Bennett W, Coughlin J, et al. Evaluating an insurer-based health coaching program: impact of program engagement on healthcare utilization and weight loss. Prev Med Rep 2018;12:343-8.

12 Ramchandani N. Virtual coaching to enhance diabetes care. Diabetes Technol Ther 2019;21:S2-48-S2-51.

13 Tate DF, Jackvony EH, Wing RR. A randomized trial comparing human e-mail counseling, computer-automated tailored counseling, and NO counseling in an Internet weight loss program. Arch Intern Med 2006;166:1620.

14 Wing RR, Phelan S. Long-Term weight loss maintenance. Am J Clin Nutr 2005;82:222S-5.

15 National Diabetes Prevention Program. Centers for disease control and prevention 2016. Available: https://www.cdc.gov/diabetes/ prevention/lifestyle-program/deliverers/eligibility.html [Accessed Dec 2018].

16 Retrofit. Retrofit Participant Terms \& Conditions. Available: https:// www.retrofitme.com/terms-conditions/ [Accessed Apr 2020].

17 National Diabetes Prevention Program. Centers for disease control and prevention. Available: https://www.cdc.gov/diabetes/prevention/ lifestyle-program/deliverers/eligibility.html [Accessed Apr 2020].

18 Painter S, Ditsch G, Ahmed R, et al. Retrofit weight-loss outcomes at 6,12 , and 24 months and characteristics of 12-month high Performers: a retrospective analysis. JMIR Mhealth Uhealth 2016;4:e101.

19 Painter SL, Ahmed R, Hill JO, et al. What matters in weight loss? an in-depth analysis of self-monitoring. J Med Internet Res 2017;19:e160.

20 Painter SL, Ahmed R, Kushner RF, et al. Expert coaching in weight loss: retrospective analysis. J Med Internet Res 2018;20:e92.

21 CDC - Diabetes Prevention Recognition Program. Centers for disease control and prevention. Available: http://www.cdc.gov/ diabetes/prevention/recognition [Accessed Dec 2018].

22 Linde JA, Jeffery RW, French SA, et al. Self-weighing in weight gain prevention and weight loss trials. Ann Behav Med 2005;30:210-6.

23 Steinberg DM, Bennett GG, Askew S, et al. Weighing every day matters: daily weighing improves weight loss and adoption of weight control behaviors. J Acad Nutr Diet 2015;115:511-8.

24 Vanwormer JJ, French SA, Pereira MA, et al. The impact of regular self-weighing on weight management: a systematic literature review. Int J Behav Nutr Phys Act 2008;5:54.

25 Fitbit. What are active zone minutes or active minutes on my Fitbit device? Available: https://help.fitbit.com/articles/en_US/Help_article/ 1379 [Accessed Dec 2018].

26 Managing overweight and obesity in adults: systematic evidence review from the obesity expert panel, 2013National Heart Lung and Blood Institute. Available: https://www.nhlbi.nih.gov/healthtopics/managing-overweight-obesity-in-adults [Accessed Sep 2019].

27 Diabetes Prevention Program Research Group, Knowler WC, Fowler $\mathrm{SE}$, et al. 10-Year follow-up of diabetes incidence and weight 
loss in the diabetes prevention program outcomes study. Lancet 2009;374:1677-86.

28 Serrano KJ, Yu M, Coa KI, et al. Mining health APP data to find more and less successful weight loss subgroups. J Med Internet Res 2016;18:e154.

29 Hutchesson MJ, Tan CY, Morgan P, et al. Enhancement of self-monitoring in a web-based weight loss program by extra individualized feedback and reminders: randomized trial. J Med Internet Res 2016;18:e82.

30 Johnson F, Wardle J. The association between weight loss and engagement with a web-based food and exercise diary in a commercial weight loss programme: a retrospective analysis. Int $J$ Behav Nutr Phys Act 2011;8:83.

31 Krukowski RA, Harvey-Berino J, Bursac Z, et al. Patterns of success: online self-monitoring in a web-based behavioral weight control program. Health Psychol 2013;32:164-70.

32 Burke LE, Wang J, Sevick MA. Self-Monitoring in weight loss: a systematic review of the literature. J Am Diet Assoc 2011;111:92-102.
33 Gilis-Januszewska A, Piwońska-Solska B, Lindström J, et al. Determinants of weight outcomes in type 2 diabetes prevention intervention in primary health care setting (the DE-PLAN project). BMC Public Health 2018;18:97.

34 Rossen J, Buman MP, Johansson U-B, et al. Reallocating bouted sedentary time to non-bouted sedentary time, light activity and moderate-vigorous physical activity in adults with prediabetes and type 2 diabetes. PLoS One 2017;12:e0181053.

35 Dwyer T, Hosmer D, Hosmer T, et al. The inverse relationship between number of steps per day and obesity in a population-based sample: the AusDiab study. Int J Obes 2007;31:797-804.

36 Turk MW, Elci OU, Wang J, et al. Self-Monitoring as a mediator of weight loss in the smart randomized clinical trial. Int J Behav Med 2013;20:556-61.

37 Sepah SC, Jiang L, Peters AL. Translating the diabetes prevention program into an online social network: validation against CDC standards. Diabetes Educ 2014;40:435-43. 